\title{
Colonialismo Interno e Estado de Exceção: a "emergência" da Amazônia dos Grandes Projetos
}

\section{Internal Colonialism and State of Exception: the "Emergency" of the Big-projects Amazon}

\author{
Bruno Cezar Malheiro \\ Doutor em Geografia pela Universidade Federal Fluminense (UFF) \\ Professor da Universidade Federal do Sul e Sudeste do Pará (UNIFESSPA), Brasil \\ brunomalheiro84@gmail.com
}

\section{Resumo}

A Amazônia, ou as Amazônias, para o Estado brasileiro, historicamente esteve/estiveram fora do Brasil. A sua inclusão pela exclusão nas políticas nacionais de desenvolvimento está figurada na homogeneização de uma diversidade que alisou ranhuras, reduziu milhares de nações a uma só, desumanizou a expressividade de vidas, reduzindo qualidades diferenciais a diferenças abissais, transformando a diversidade regional em vazio: de pessoas, de técnica e de política. Na esteira dessa ausência, os grandes projetos emergem como dispositivos políticos capazes de desempenharem, não apenas a drenagem de matéria e energia por meio do saque neocolonial e reproduzirem a dependência como mote de integração global, mas por tornarem possível o uso da violência como processo de acumulação, por tornarem possível a expropriação das condições de existência e energias vitais de povos e comunidades tradicionais como lógica legitimada de desenvolvimento, tornando o sacrifício, a destruição e a morte em caminhos naturalizados do que se institui colonialmente como progresso. Esse artigo pretende percorrer a produção dessa não existência da Amazônia em relação ao Brasil analisando as figurações dos dispositivos de nacionalidade brasileira que definiram a Amazônia como risco à soberania e um vazio para o qual se justificam grandes projetos como dispositivos de exceção.

Palavras-chave: colonialismo interno, estado de exceção, grandes projetos, territorialização de exceção.

\begin{abstract}
The Amazon, or the Amazons, has/have historically been outside of Braziltothe Brazilian Government. Its inclusion by the exclusion of national development policies materialised in a diversity homogenisation which has smoothed the grooves, reduced millions of nations into only one, and dehumanised lives' expression. In this way, it has reduced differential qualities into abyssal differences, transforming the regional diversity into a void: of people, of techniques and politics. In the wake of this absence, the big projects emerge as political devices capable of carrying out not only the drain of matter and energy by way of a neocolonial sacking, which reproduces the dependency as a global integration motto; but they also enable the use of violence as an accumulation process. They also enable the expropriation of the existing conditions and the vital energy of peoples and traditional communities as the legitimised development rationale. In this way, the sacrifice, the destruction and the death become a naturalised path of what is colonially established progress. This paper aims to cover the production of this Amazon's non-existence concerning Brazil, analysing the figurations of the Brazilian nationality's devices which have defined the Amazon as a risk to the sovereignty and as a void to which the big projects are justified as exception devices.
\end{abstract}

Keywords: internal colonialism, state of exception, big projects, territorialisation of exception. 


\section{INTRODUÇÃ̃}

Aqui a gente toma guaraná quando não tem Coca-Cola Chega das coisas da terra que o que é bom vem lá de fora Deformados até a alma sem cultura e opinião O nortista só queria fazer parte da nação

Edmar Rocha e Mosaico de Ravena

O trecho da música que dá ritmo à epígrafe, oficialmente reconhecida por premiações musicais de âmbito nacional e internacional, na categoria de música regional, canta, em verso e canção, a total ausência da Amazônia do imaginário nacional brasileiro. O reclamo musical ganha os timbres de vozes que reverberam, à flor da pele, o significado de estar ausente das grades de uma interpretação de Brasil.

$\mathrm{Na}$ esteira dessa ausência, o romancista amazonense Marcio Souza dá dois exemplos contundentes no campo científico, em que a Amazônia se torna um espaço culturalmente marginal. O primeiro exemplo são os três volumes da coleção Intérpretes do Brasil, lançada em homenagem aos quinhentos anos do "descobrimento", na qual não há uma única linha sobre Amazônia, enquanto o segundo exemplo é o volume Hispanic American Historical Review, com o tema “começos brasileiros”, em que a região também é simplesmente ignorada (SOUZA, 2015).

Vários foram os pesquisadores que nos mostraram que a Amazônia é, em síntese, uma invenção. Uma invenção que já foi lida pela crítica às representações sobre e não da Amazônia (PORTO-GONÇALVES, 2005); a partir das representações dos viajantes e naturalistas (GONDIM, 2004; ALMEIDA, 2008; PIZARRO, 2012); a partir dos ensaios de José Veríssimo, Euclides da Cunha, Leandro Tocantins e Eidorfe Moreira (PEREIRA, 2016); ou ainda a partir dos discursos propalados por intermédio dos meios de comunicação (DUTRA, 2003).

A Amazônia, ou as Amazônias, para o Estado brasileiro, historicamente esteve/estiveram fora do Brasil. Tal afirmação encara que os discursos que inventaram o Brasil são práticas espaciais que carregam imaginários coloniais, sendo o espaço, nesse caso a região, também um produto de versões da história. As políticas nacionais para a Amazônia transformam esquemas de percepção em práticas espaciais ao pretenderem tornar o lugar distante uma região mais próxima da nação. Essa inclusão pela exclusão alisou ranhuras, reduziu milhares de nações a uma só, desumanizou vidas, transformando qualidades diferenciais em diferenças abissais e diversidade em vazio. Esse artigo pretende problematizar a produção dessa não existência da Amazônia em relação ao Brasil analisando, a partir dos discursos políticos oficiais, as figurações dos dispositivos de nacionalidade brasileira que definiram a Amazônia como risco à soberania e um vazio para o qual se justificam Grandes Projetos como dispositivos de exceção. 
Para isso, primeiro, chamamos para a discussão os conceitos de colonialismo interno e estado de exceção, entendendo-os como sínteses analíticas fundamentais do sentido das políticas nacionais para a Amazônia. Em um segundo e terceiro momento, interrogando a emergência da Amazônia como um risco à soberania, observamos os processos de normalização das práticas de exceção, o que nos leva a uma reflexão, na quarta parte do texto, acerca da emergência dos grandes projetos como dispositivos políticos de exceção.

\section{COLONIALISMO INTERNO E ESTADO DE EXCEÇÃO}

A identidade nacional brasileira já é, em si, uma expressão prática das marcas de colonialidade que vestiram de verde e amarelo uma imagem cujos parâmetros se definem no contraste com o colonizador, sendo moldada pela sua referência.

A identidade nacional pressupõe a relação com o diferente. No caso brasileiro, o diferente ou o outro, com relação ao qual a identidade é definida, são os países capitalistas desenvolvidos, tomados como se fossem uma unidade e uma totalidade completamente realizadas. É pela imagem do desenvolvimento completo do outro que a nossa identidade, definida como subdesenvolvida, surge lacunar e feita de faltas e privações (CHAUÍ, 2004, p. 27).

Chauí (2004) aponta a colonialidade - essa vontade de saber e de poder que nos reconstrói a imagem e semelhança do outro que nos violenta - como o elemento central de construção de uma identidade nacional brasileira. Entretanto, não desconsiderando esses termos da colonialidade, queremos advertir que a identidade nacional também escolhe, dentro do território nacional, aqueles que mais se assemelham aos parâmetros eurocêntricos que as define e, assim, ignora espaços e tempos que não apareçam nesse espelho que é o olhar nacional.

É por esses termos que encontramos o conceito de colonialismo interno, noção definida por Pablo Gonzáles Casanova, mas que encontrou grandes rebatimentos na teoria antropológica brasileira. O conceito se nutre da compreensão de que o colonialismo não "deve apenas contemplar a escala internacional”, pois "se dá no interior de uma mesma nação, na medida em que há nela uma heterogeneidade étnica em que se ligam determinadas etnias com os grupos ou classes dominantes, e outras com os dominados" (GONZÁLEZ CASANOVA, 2006, p. 401).

De modo mais explicativo, o mesmo autor diria que:

el colonialismo interno corresponde a una estructura de relaciones sociales de dominio y explotación entre grupos culturales heterogéneos, distintos. Si alguna diferencia específica tiene respecto de otras relaciones de dominio y explotación (ciudadcampo, clases sociales), es la heterogeneidad cultural que históricamente produce la conquista de unos pueblos por otros, y que permite hablar no sólo de diferencias culturales (que existen entre la población urbana y rural y en las clases sociales), sino de diferencias de civilización (GONZÁLEZ CASANOVA, 2015, p. 146). 
Atribuindo a genealogia de seu conceito a Lênin, Gramsci, Mariátegui e Frantz Fanon, Gonzáles Casanova, nesse particular, indica, como uma leitura que amplia os sentidos de colonialismo interno, as interpretações de Antônio Gramsci (2002) sobre as relações desiguais, violentas ou "sanguessugas", nos termos do autor, entre as regiões norte e sul da Itália. Nesse sentido, a dinâmica de violação étnica na estruturação de uma nação se combina com relações desiguais entre regiões, construindo um sistema de domínio territorial e étnico, alargando estratégias de conquista e controle, concomitantemente ao empreendimento de políticas de tutela e extermínio de povos. A raça e os processos de classificação social tornam-se, assim, elementos estruturais de produção de hierarquias para justificar dominações; razão pela qual a dinâmica do colonialismo interno é, também, da colonialidade do poder ${ }^{1}$.

Roberto Cardoso de Oliveira, que publica o texto "Aculturação e Fricção interétnica" no mesmo número da revista América Latina que Gonzáles Casanova organizou os termos conceituais do colonialismo interno, reivindica que seus trabalhos e de vários outros antropólogos brasileiros podiam ser pensados a partir do escopo desse conceito, uma vez que o colonialismo interno constrói um trânsito de escalas, pois, tributário dos conceitos da sociologia do subdesenvolvimento, ajuda a fazer a mediação entre análises mais centradas nas particularidades étnicas dos grupos sociais, com os processos de construção da sociedade nacional, dando destaque aos grupos étnicos por participarem da condição de existência da pluralidade da sociedade (OLIVEIRA, 1963, 1972). Sua noção de fricção interétnica, definida como uma "situação de contato entre duas populações dialeticamente 'unificadas' através de interesses diametralmente opostos, ainda que interdependentes" (OLIVEIRA, 1996, p. 47), também foi pensada para entender o contato entre o que se definiu por sociedade nacional e os indígenas.

Nesses termos, tomamos consciência que as violações aos povos e comunidades tradicionais, ou seja, o extermínio da nossa diversidade social, cultural e cosmológica, apresenta uma continuidade histórica entre o colonialismo de bandeira européia e o nascente colonialismo interno, verde e amarelo, atrelado a interesses transnacionais, impregnado de um nacionalismo marcado por um imaginário que naturaliza a violência aos grupos étnicos e o esquecimento de seus territórios de referência, bem como das regiões em que se fazem mais presentes.

A unidade nacional, tão apregoada pelos ideólogos nacionalistas, de esquerda e de direita, nada mais é que uma forma de construção de um imaginário para o exercício do poder pelo Estado. Interrogando os sentidos da ideia de nação e consciência nacional, Anderson (2008) adverte que

\footnotetext{
${ }^{1}$ No processo de colonização da América Latina, por meio da colonialidade do poder, criaram-se identidades sociais novas, como índios, negros e mestiços para, deliberadamente, e de forma violenta, unificar a diversidade cultural e epistêmica desta região e, a partir da ideia de raça, legitimar relações de dominação marcadas por critérios de superioridade/inferioridade entre os dominantes e os dominados; fato que definiu uma divisão racial do trabalho, mas fundamentalmente, estabeleceu o controle europeu de todas as formas de subjetividade, cultura e produção do conhecimento até então estabelecidos (QUIJANO, 2009). 
precisamos diferenciar a modernidade objetiva das nações e a antiguidade subjetiva, que nada mais é que o imaginário nacionalista. Nesse particular, o mesmo autor ressalta que a nação é fundamentalmente imaginada em seus membros, que nunca se conhecerão por completo, em seus limites, que dificilmente se saberá ao certo, em sua soberania, que sempre abarcará pluralidades vivas, e em sua comunidade, que também dificilmente será fraterna e totalmente coesa (ANDERSON, 2008).

Dois aspectos da nação são de fundamental importância: o primeiro deles é que as nações são camadas discursivas que produzem realidade e verdade por sua figuração e imaginação; e o segundo é que sua matriz discursiva se funda na ideia de modernidade. Imaginário, como explica Mignolo (2005), é a forma que uma sociedade define a si mesma, ou ainda, a produção social e psíquica incessante de figuras, formas e imagens que criam o que conhecemos por realidade (CASTORIADIS, 1982, p.13). Modernidade, por sua vez, como ensina Castro-Gomes (2005, p. 169), pode ser entendida como "uma máquina geradora de alteridades que, em nome da razão e do humanismo, exclui de seu imaginário a hibridez, a multiplicidade, a ambigüidade e a contingência de formas de vida concretas". A nação, produção do imaginário moderno-colonial, passa a ser um dispositivo político de definição dos que estão dentro e os que estão fora da política.

O ordenamento jurídico que indicia e, posteriormente, cristaliza os Estados Nacionais, fundam-se, como nos lembra Agamben (2015), nas noções de natividade e soberania. Nascer no seio de um Estado confere cidadania, estar dentro daquilo que se define por nação é, enfim, o passaporte para uma vida política, uma vez que os direitos do homem não são abstratos, porque são direitos de homens de um Estado. Mas se a cidadania, o direito e a própria vida, existem em função de uma definição nacional, a ideia de nação, mostra-se, em síntese, como já dito, como um dispositivo potente para definir quem está dentro e quem está fora da política. Nascer em um Território Nacional confere uma natividade que poderia sugerir direitos, entretanto, nascer em um território nacional não significa nada se não se está incluído nas figurações, discursos, imagens, recortes e projeções que marcam e demarcam o que significa ser uma nação.

Por esse motivo, particularmente na Amazônia, para onde se projetam tantos e tantos ideais de Nação, estamos vendo se elevar o número de refugiados, pessoas que nasceram no país, à beira de uma mina de ferro, de uma hidrelétrica, na estreita relação com a floresta, mas que não cabem na política, pois viram entraves à nação, rostos que não se refletem no espelho que se convencionou chamar de Brasil. Refugiados brasileiros no Brasil, brasileiros demais para a estatística, brasileiros de menos para o direito. A nação e suas figurações são, portanto, formas de tornar ausente o que está presente, de esconder com o brilho de discursos, imagens e convicções políticas e científicas, o que não se quer enxergar, o que não se nota pelo lugar de onde se olha. 
É um dispositivo de nacionalidade brasileira, esse "conjunto de regras anônimas que passa a reger práticas e discursos [...] e que impunha aos homens a necessidade de ter uma nação, de superar suas vinculações localistas e se identificarem com um espaço e um território imaginários" (ALBUQUERQUE JR., 2006, p. 48) que, assim, define zonas de penumbra, regiões distantes do imaginário nacional e, por isso, sempre representadas pelo perigo à soberania, para onde tudo parece permitido.

O colonialismo interno, pelos seus dispositivos de nacionalidade, define práticas de suspensão da ordem jurídica inscritas num "patamar de indeterminação entre a democracia e o absolutismo" (AGAMBEN, 2004, p. 13), define, enfim, zonas de indiferença, regiões habitadas por seres viventes que possuem uma vida matável, em que a morte não é considerada crime nem sacrifício, pois é excluída do mundo do direito e do mundo divino, o que torna possível a sujeição da vida a um poder de morte, uma biopolítica que justifica o estado de exceção como regra.

Esse diálogo conceitual entre matrizes metodológicas distintas é necessário, pois os processos de formação nacionais carregam marcas biopolíticas do estado de exceção, principalmente nas regiões que não cabem no imaginário nacional difundido, ou seja, pensar as políticas nacionais para a Amazônia é compreender de que maneira os processos de colonialismo interno se realizam por práticas de suspensão normativa tornando a exceção a regra.

\section{A AMAZÔNIA E A SOBERANIA NACIONAL: A EMERGÊNCIA DE UM RISCO}

Frequentemente, as interpretações sobre a parte brasileira da Amazônia não dão a devida importância a um fato primordial. É que a América Portuguesa não estava constituída por uma única, e sim por duas colônias distintas: a do Brasil, cuja sede permaneceu em Salvador por mais de dois séculos, abrangendo da capitania de São Vicente (São Paulo) ao Ceará, incorporando o litoral, a Mata Atlântica, e se desdobrando para os sertões do rio São francisco; e a do Mato Grosso e Grão-Pará, cuja sede foi a cidade de Belém, próximo à embocadura do rio Amazonas, tendo como sua hinterlândia toda a região configurada pelo enorme vale deste rio e de seus numerosos afluentes. Não se trata de um detalhe da vida política-administrativa portuguesa, mas a instituição de dois modelos de colonização, com estratégias bastante diferentes de incorporação das populações autóctones e de utilização dos recursos naturais (PACHECO DE OLIVEIRA, 2016, p. 161, grifo do autor).

A tese de João Pacheco de Oliveira é potente e importante. Na Amazônia, o extrativismo das chamadas drogas do sertão, com força de trabalho indígena, arregimentada por meio da catequeze, erigiram uma dinâmica colonial própria e distinta da então usada no "Brasil". A tese de dois regimes de colonização distintos constitui-se em questão concreta se percebermos que, em 1621, sob ordens de Filipe III de Espanha, no período da união ibérica entre Portugal e Espanha, a América Portuguesa foi dividida em duas unidades administrativas plenamente autônomas: a primeira, o Estado do Maranhão, que seria a América Portuguesa setentrional, com capital em São 
Luís, e a segunda, o Estado do Brasil, a parte sul dos domínios ibéricos na América, cuja capital era Salvador.

As particularidades desses processos coloniais conferem aos padres das missões, entre os séculos XVII e XVIII, uma grande centralidade, uma vez que estes possuíam o monopólio de quase todas as operações que geravam valor: da produção e coleta das drogas do sertão, da exploração do trabalho indígena, ao transporte e venda dos bens comercializáveis. Essa particularidade, entretanto, irá se configurar na condição de emergência de uma forma de ver e dizer a região, justamente quando a importância dos missionários soar como uma ameaça à soberania do Estado.

Marquês de Pombal, em Instrução Régia enviada em 1751 a Mendonça Furtado - seu primo que fora indicado à presidência da Província do Maranhão e Grão Pará (que depois seria chamada de Grão Pará e Maranhão) - já constatava que "como à minha real notícia tem chegado o excessivo poder que têm nesse Estado os Eclesiásticos” (MELO, 1989, p. 8). Na mesma Instrução, torna-se bem mais claro seu receio com os padres:

Pois que, ignorando os miseráveis índios que havia na terra poder que fosse superior ao poder dos Padres, criam que esses eram soberanos despóticos dos seus corpos e almas; ignorando que tinham um rei a quem obedecer [...] ignorando enfim que haveria leis que não fossem as da vontade dos seus Santos Padres (assim os denominavam) [...]. Recomendo-vos muito que procureis atentamente os meios de segurar o Estado, como também os de fazer florescer o comércio (MELO, 1989, p. 8).

A violenta leitura colonial e eurocêntrica das populações autóctones agrega-se a um problema concreto para a soberania do Estado português, qual seja: a enorme legitimidade das ordens religiosas faz com que o Estado não seja uma realidade objetiva para as populações amazônicas.

A preocupação com a soberania da parte setentrional da América Portuguesa com a política pombalina ${ }^{2}$ se expressa não apenas a partir de ameaças externas, mas fundamentalmente por riscos internos, o que marcará as condições de emergência de uma forma de ver a Amazônia.

No início do século XIX ${ }^{3}$, após a contraditória declaração da independência do Brasil ${ }^{4}$, mais especificamente durante o período do segundo reinado de Dom Pedro II, João Antônio de

\footnotetext{
${ }^{2}$ É importante notar que mesmo antes do reinado de Dom José em Portugal, a partir de 1750, e da nomeação do Marquês de Pombal para Secretário de Negócios Estrangeiros e de Guerra, a coroa portuguesa já demonstrava preocupações com a definição de suas fronteiras, expressas em dois tratados: o Tratado de Utrecht (1715), firmado entre França e Portugal, no qual ficou reconhecido a soberania de Portugal da margem esquerda do Rio Amazonas e a da França das terras próximas ao Rio Oiapoque, hoje Guiana Francesa; e o Tratado de Madri (1750), em que a Espanha reconheceu o domínio de Portugal sobre as terras ocupadas pelos luso-brasileiros. Entretanto, é Pombal que vai tornar central a segurança e definição de fronteiras, com especial destaque à Amazônia, vista enquanto risco à soberania portuguesa.

${ }^{3} \mathrm{Na}$ Constituição de 1824, três títulos de nobreza foram criados aos herdeiros do império: o de príncipe, príncipe imperial e príncipe do Grão-Pará. A distância e a vulnerabilidade da, então, maior província, motivou a criação do título nobiliário para simbolizar a integridade do Império brasileiro.
} 
Miranda - presidente da Província do Pará no ano de 1840, província que acabara de passar por uma das maiores revoltas populares da história, a Cabanagem, movimento violentamente massacrado após a ofensiva do Império - afirma o seguinte em seu discurso à Assembleia Legislativa Provincial, "tenho toda a esperança, senhores, que uma inspiração patriótica chamará em torno dos interesses próprios, dos interesses da província [...]. As circunstâncias são mui prósperas, o futuro mui risonho, e a Província do Pará [...] exige sacrifícios, constância e Brasileirismo".

O tom otimista, nutrido do sangue derramado de cabanos pelo Império brasileiro, retoma novamente a necessidade de pensar a administração dessa porção do território agora chamado de nacional, a partir de sacrifícios e de brasileirismo. Alguns anos mais tarde, o já presidente da província do Amazonas, antiga comarca do Rio Negro, João Dias Vieira, reclamava dos abusos que cometem os missionários religiosos em relação às populações indígenas. Diz ele:

São, além disto, por mais exíguas as somas voltadas anualmente para esta verba, de modo que não é possível emprehender-se com probabilidade de sucesso qualquer ensaio de organização de aldêas nos pontos mais salientes, como os das fronteiras com os paizes limitrophes estrangeiros, para cujas brenhas se estranhão tribus nossas ao menor desgosto, proveniente quasi sempre dos abuzos, que comettem, em nome do Governo e sob o pretexto de serviço publico - os diversos Encarregados d'ellas, tornando assim entre os Indios odioza a ideia de autoridade, que alias se lhes deve infundir como é - benéfica e protectora 6 .

As nações indígenas, logicamente com outros referenciais para definição de seus territórios, são vistas como vulneráveis aos abusos dos encarregados por elas, geralmente missionários, o que, em situações de fronteiras, representa risco à soberania.

No século XIX, após a expulsão dos jesuítas ainda no século XVIII e a criação, pela administração pombalina, do Diretório dos Índios em 1758 e sua extinção em 1798, é só em 1845, com o Regulamento das Missões, que o Império institui, inspirado no Diretório, uma política indigenista ligada ao Estado, na qual se propõe uma administração leiga dos indígenas com diretores do Estado juntamente com missionários sendo nomeados às aldeias (CUNHA, 2012). A função da igreja, particularmente na Amazônia, é um tanto ambígua nesse contexto, uma vez que embora no regulamento apareça que os missionários devam ser apenas assistentes religiosos e educacionais do administrador, o que ocorre é que "talvez pela carência de diretores de índios [...] é

\footnotetext{
${ }^{4}$ A declaração de independência preservou o sistema político português, tendo como líder o herdeiro da Coroa lusitana, que sustentou a escravidão e a mesma elite política e econômica.

${ }_{5}$ Discurso recitado por João Antonio de Miranda, presidente da província do Pará na abertura da Assembleia Legislativa Provincial, no dia 15 de agosto de 1840.

${ }^{6}$ Exposição feita pelo Presidente da Província do Amazonas, João Dias Vieira, a Manuel Gomes Corrêa de Miranda, por ocasião da passagem da administração provincial, em 26 de fevereiro de 1857, p. 20. 
freqüentíssima a situação de missionários que exercem cumulativamente os cargos de diretores de índios" (CUNHA, 2012, p. 69).

É particularmente referenciando o perigo que significa os diretores dos índios - que são missionários, em sua maioria - em não fortalecer a autoridade do Estado, que o presidente da província do Amazonas, em 1864, Manoel Clementino Carneiro, exclama:

O trabalho da catechese é dedicado, exige despezas, sacrifícios e muito esforço. Por simples honras militares ninguém deixará seus commodos e interesses, e os de sua família para internar-se por sertões desertos, residir entre os gentios e cuidar da diffícil e enfadonha questão de sua civilização. Esperar tanto é supor o inexeqüível e desconhecer as condições da vida prática. A experiência de todos os dias confirma este pensamento. Os directores parciaes não correspondem ás vistas da lei, e são poucos os que não convertem em utilidade própria o cargo estabelecido para beneficio publico $^{7}$.

A imagem do indígena como selvagem, encarnada na palavra gentio, permanece com a força destrutiva e violenta de se justificar uma missão "civilizatória". Entretanto, a representação da região como um sertão deserto e a enfadonha tarefa de se relacionar com os índios, são colocados como elementos explicativos da mudança do sentido de autoridade estabelecida pelos diretores de índios. Se as ordens religiosas representavam um Estado dentro do Estado ainda no século XVIII, cem anos depois, os diretores de índios significarão o mesmo problema.

Mesmo com a Proclamação da República, no ano de 1889, sua parte setentrional ainda continua representando risco. Nesse sentido, se os presidentes da província do Pará reivindicavam brasileirismo, os agora governadores do Estado, outrossim, também se apoiam nessa formação discursiva, como expressa o discurso de José Paes de Carvalho ao Congresso do Estado do Pará, em 7 de abril de 1898:

O erro capital dos jesuitas foi querer sequestrar os indigenas nos seus respectivos aldeiamentos e priva-los assim do contacto com os agricultores; era fatal que semelhante organização, que obedecia quase exclusivamente a sentimentos religiosos, ser indiferente á existencia de um Estado no Estado. Não cometteremos as mesmas faltas ${ }^{8}$.

O discurso de Paes de Carvalho em muito se assemelha às preocupações de Marquês de Pombal e Mendonça Furtado. Nesses termos, o erro dos jesuítas é a marcação de um problema histórico, de uma região indiferente à existência de um Estado. A soberania do Rei, do Imperador, do Presidente da Província ou mesmo do Governador do Estado, sempre foi uma questão. A necessidade de se fazer ver o Estado do Pará no Estado Brasileiro e toda lógica nascente de uma República federativa, vira o sentido maior da política.

\footnotetext{
${ }^{7}$ Relatório de Manoel Clementino Carneiro da Cunha, presidente da província do Amazonas, à Assembleia Legislativa Provincial, em 1864, p. 16.

${ }^{8}$ Mensagem de José Paes de Carvalho ao Congresso do Estado do Pará ao Congresso do Estado do Pará, em 7 de abril de 1898 , p. 28. 
Um pouco tempo depois desse discurso de Paes de Carvalho, um ato simbólico registrava a definitiva necessidade de se demonstrar que este recanto do nascente país era uma região conquistada em definitivo. O governador do Pará, Augusto Montenegro, em mensagem ao Congresso Legislativo do Estado do Pará, em 7 de setembro de 1905, falando da decoração do palácio de governo, informa aos presentes que:

Para a parede do fundo deste salão encomendei ao consagrado pintor brasileiro Antonio Parreiras, uma grande tela de 8 metros sobre 4, denominada a Conquista do Amazonas. Este quadro representará o acto de Pedro Teixeira tomando conta das terras da Amazonia para a corôa de Portugal ${ }^{9}$.

Não era apenas um quadro senão uma representação das obrigações do governo. A conquista só é uma questão em uma região em que a soberania é uma questão. Portanto, a decoração com o quadro de Antônio Parreiras é a síntese dessa formação discursiva em que a Amazônia é um problema à política nacional.

Questões de soberania nacional na Amazônia rondaram boa parte dos primeiros anos do século XX. Apenas em 1903 que o que hoje conhecemos como Acre foi definitivamente incorporado ao Brasil e, em 1904, o presidente Rodrigues Alves editava o Decreto-Lei $\mathrm{n}^{\circ}$ 5.188, que construía uma figura jurídica nova, transformando o Acre em Território Federal, cujos governadores e prefeitos seriam nomeados e subordinados à presidência. $\mathrm{O}$ risco à soberania nacional foi respondido, então, com a criação de uma entidade jurídica que vincula toda segurança e administração local ao poder central.

Não muito distante em termos de linearidade histórica e próximo em termos de formação discursiva, um conjunto de outros discursos, basicamente circunscritos na nova república do Brasil na década de 1930, envolvem a Amazônia por sua distância ao poder central do Brasil. No famoso Discurso do Amazonas, proferido em 1940 na cidade de Manaus, Getúlio Vargas afirma que “[...] é natural que uma imagem tão forte e dramática da natureza brasileira seduza o povo e as imaginações moças prolongando-se em duradouras ressonâncias pela existência em fora" (VARGAS, 1940 apud SUDAM, 1968, p. 9).

A Amazônia no discurso é vista como a natureza brasileira, ou seja, como uma exterioridade à humanidade brasileira, ou ainda, como uma região situada enquanto natural em uma linha civilizatória em que natureza representa imaturidade/inferioridade e a sociedade representa o progresso histórico. Entretanto, todas essas concepções, associam-se a um problema de fundo: a existência desta porção do território como um fora. Por isso, continua Vargas:

\footnotetext{
${ }^{9}$ Mensagem de Augusto Montenegro ao Congresso Legislativo do Estado do Pará, em 7 de setembro de 1905 , p. 64. 
Nada nos deterá nessa arrancada que é, no século XX, a mais alta tarefa do homem civilizado: conquistar e dominar os vales das grandes torrentes equatoriais, transformando sua força cega e a sua fertilidade extraordinária em energia disciplinada [...] Ao homem moderno está interdita a contemplação, o esforço sem finalidade. E a nós, povo jovem, impõe-se a enorme responsabilidade de civilizar e povoar milhões de quilômetros quadrados. Aqui, na extremidade setentrional do território pátrio, sentindo essa riqueza potencial imensa que atrai cobiças e desperta apetites de absolvição, cresce a impressão dessa responsabilidade, a que não é possível fugir, nem iludir. Sois brasileiros e aos brasileiros cumpre ter consciência de seus deveres, nessa hora que vai definir os nossos destinos de Nação (VARGAS, 1940 apud SUDAM, 1968, p. 10 e 11).

Todo o ideal civilizatório atrelado a uma ficção nacionalista que representa a Amazônia como uma força cega de fertilidade extraordinária, na verdade se traduz na necessidade premente, que, inclusive, nada pode deter, de conquistar e dominar para a nação essa porção setentrional do que vai se chamar de Brasil. O moderno da energia disciplinada, que civiliza e povoa, não existiria se não fosse pela invenção deste fora absoluto dos ideais de nacionalidade. O jogo de polarizações e dicotomias é a ferramenta encontrada para controlar os perigos de absolvição e a cobiça dos estranhos. A nação vira o remendo entre a garantia de soberania e os sentidos de autoridade de uma comunidade imaginada por uma imagem, na qual não cabem os mundos, visões, figuras, línguas, espaços, territórios, existências dessa chamada torrente equatorial ${ }^{10}$.

A imagem de um fora irredutível da região, leva a uma urgência na política. Assim, ocupação e valorização foram as palavras de ordem da criação da Superintendência de Valorização Econômica na Amazônia (SPVEA), em 1953.

Com objetivos de assegurar à ocupação da Amazônia um sentido brasileiro, construir na Amazônia uma sociedade economicamente estável e progressiva capaz de, com seus próprios recursos, prover a execução de suas tarefas sociais e desenvolver a Amazônia num sentido paralelo e completar ao da economia brasileira... (SPVEA, 1954, p. 4).

Dessa maneira, torna-se necessário assegurar à ocupação da Amazônia um sentido brasileiro, não se tratando, portanto, apenas de ocupar, mas, sim, de desenvolver os sentidos do Brasil nesta região. Mediante esta urgência, o primeiro plano regional de desenvolvimento, erigido pela SPVEA, chamou-se plano de emergência.

Ao problema da Amazônia fora do Brasil, associam-se discursos correlatos que, definidos a partir de um lócus de enunciação distante da região, embora assumidos por muitas políticas definidas a partir da região, demarcam o vazio como elemento definidor desta parte setentrional da

\footnotetext{
${ }^{10}$ Uma marca expressiva desse regime de verdade foi, em 1943, a instituição, por Vargas, por meio do Decreto $\mathrm{n}^{\circ}$ 5.812, dos territórios federais do Amapá, Rio Branco (que passou, em 1962, a se chamar Território Federal do Roraima), do Guaporé (que em 1956 passa a ser chamado Rondônia), além de Ponta Porã e Iguaçu. Dos cinco Territórios Federais criados, três estão na Amazônia, notadamente aqueles que, em suas fronteiras, representavam um risco concreto à soberania. Outrossim, vale lembrar que por meio desse decreto também se criou a guarda territorial, responsável por manter a ordem interna no território nacional.
} 
América portuguesa, ou como afirma Dutra (2003, p. 73), "a negação da existência de seres humanos supõe a afirmação da existência de um vazio humano que está aí para ser preenchido".

Esse esvaziamento de sentido das existências amazônicas ganhou notoriedade científica por um conjunto de concepções de Amazônia como vazio demográfico. A imagem de região despovoada pode ser bem expressada a partir da afirmação de Eidorfe Moreira, para quem:

o que mais nos fere a atenção e sobremodo confrange quando observamos a paisagem amazônica de baixo de um ponto de vista ou consideração humana, é a reduzida significação que o homem assume nela [...]. Realmente a mais extensa das regiões do país é também a mais carenciada sob o ponto de vista demográfico (MOREIRA, 1958, p. 67).

Nesses termos, a ciência legitima uma imagem regional a qual se efetiva e desenha contornos reais em políticas que, também, por seu turno, serão celebradas por intelectuais, como o faz outro geógrafo bastante influente, Lúcio de Castro Soares (1963, p. 187):

Obra política, pela qual a nação procura desenvolver economicamente os espaços inaproveitados do território brasileiro, a valorização econômica da Amazônia é um empreendimento de vulto, cujos objetivos maiores podem ser definidos como um esforço nacional para: a) assegurar a ocupação da Amazônia em sentido brasileiro; b) construir na Amazônia uma sociedade economicamente estável (...); c) desenvolver a Amazônia num sentido paralelo e complementar ao da economia brasileira.

Não sem razão, Almeida (2008), analisando o que definiu como antropologia dos archivos da Amazônia, chega a definir esses arquivos por seu biologismo e por seu geografismo. Dicotomias como natureza-cultura, racional-irracional, cheios-vazios alimentaram noções como "vazio demográfico", "povoamento", “desenvolvimento" e, assim, “este conjunto de oposições marca, por assim dizer, todo um conjunto de planos e programas oficiais para a Amazônia e em particular sobre a 'natureza' na Amazônia" (ALMEIDA, 2008, p. 32). Esses geografismos e biologismos, por seu turno, marcam modos de olhar que se transformam em modos de conduzir a política. Boaventura de Sousa Santos (2008) demonstrou bem que a colonialidade das "descobertas" imperiais inclui a representação da natureza tanto como o lugar da exterioridade e do selvagem, quanto o lugar da inferioridade. A Amazônia, entre esses dois sentidos, torna-se definitivamente um risco, não apenas por representar a exterioridade irracional da natureza, mas também a inferioridade abissal de suas populações. A Amazônia como risco entra na política para estar fora, pois faz ver algo absolutamente distinto do que se estabelecerá como coroa, império ou república. 


\section{NORMALIZAÇÕES DO RISCO AMAZÔNICO: A POLÍTICA COMO GUERRA E A EXCEÇÃO COMO REGRA}

Os governos militares no Brasil consolidam esta formação discursiva transformada em política (traduzida nos ideais de integrar, ocupar e desenvolver ${ }^{11}$ ), incorporando a ela a doutrina de segurança nacional. Como síntese desse esboço, a chamada "Operação Amazônica", um conjunto de leis federais, decretos, isenções fiscais e grandes obras de infraestrutura, consolida a Amazônia como questão nacional de um Estado que, em nome da segurança, torna a exceção a regra da política.

O discurso do primeiro superintendente da SUDAM, General Mário Barros Cavalcanti, recuperando a formação discursiva da Amazônia como risco à soberania, transforma esse modo de ver em uma forma de exercício do poder:

A história das grandes nações tem suas passagens mais belas no capítulo dos sacrifícios [...]. Os povos que nada sofreram não possuem histórias para contar. Nessa ordem de raciocínio situamos a Amazônia no processo de construção e transformação do Brasil. Os séculos de luta da gente lusitana para conquistar terra inóspita; a dedicação missionária para conquistar o selvagem arredio e, mais tarde, o esforço brasileiro de conservá-la conosco, eis algumas passagens de bravura e sacrifício que fizeram da Amazônia nosso capítulo de sofrimento [...]. De um lado, na parte sul, aquele pais desenvolvido cujos padrões de progresso nos colocam em pé de igualdade com os centros mais avançados do mundo. De outro, todavia, no extremo norte o que vemos é a chaga terrível do subdesenvolvimento [...]. Por isso, concebeu e lançou as bases da Operação Amazônia, para se situar à frente dos mais graves problemas do nosso tempo que consiste, exatamente, na conquista e conseqüentemente aproveitamento dos grandes espaços vazios, utilizando-os em benefício do homem. Somente assim, povoando, desenvolvendo e conquistando de modo efetivo a Amazônia, estaremos fazendo uma guerra pela paz, desarmando os espíritos e convidando todos os homens para um trabalho conjunto (CAVALCANTI, 1966 apud SUDAM, 1968, p. 73-74).

Dicotomias como desenvolvimento e subdesenvolvimento, cheio e vazio, sul e norte, terra próspera e terra inóspita são manejadas para construir uma fila histórica em que a Amazônia é o extremo oposto do que se quer como nação, para, assim, justificar um modo específico de fazer política como guerra. Nessa construção, três são os conquistadores: os missionários, os lusitanos e o Estado Brasileiro, o que expressa que é a chegada de gente de fora que define a existência de um espaço, pois aos povos de dentro só lhes é reservada a caricatura do selvagem arredio de espíritos armados. Nesses termos, a região amazônica se torna um espaço de sacrifícios, tão terrível que

\footnotetext{
${ }^{11}$ Os ideais de integrar, ocupar e desenvolver a região amazônica foram materializados em ações concretas que, desde a criação da SPVEA, em 1953, da abertura da BR-010 (Belém- Brasília), em 1958, e da BR-364 (Cuiabá-Porto Velho) em 1960, configuraram-se em um conjunto integrado de ações e implementações de um novo sistema técnico no território amazônico. Salienta-se que estas ações alargaram-se com os governos militares a partir da criação da Superintendência do Desenvolvimento da Amazônia (SUDAM), em 1966, e da Superintendência da Zona Franca de Manaus (SUFRAMA), em 1967, bem como por meio do Plano de Integração Nacional, de 1970, e dos três Planos de Desenvolvimento da Amazônia (o primeiro entre 1972-1974, o segundo 1975-1979 e o terceiro entre 1980-1985); sem esquecer, do Programa que, talvez, sintetize o conjunto das pretensões e estratégias dos governos militares para a Amazônia, que foi o Programa Grande Carajás (PGC).
} 
precisa ser ocupado a qualquer custo; fato que, discursivamente, transforma a violenta chegada do estranho numa bravura histórica de um projeto nacional.

Diante da imagem projetada, ações enérgicas de ocupar, conquistar e desenvolver se tornam necessárias, como uma guerra pela paz para desarmar os espíritos. A guerra não é só uma metáfora, é a expressão clara de um lugar indistinto, na qual tudo pode ocorrer para se chegar ao sentido de desenvolvimento inventado. A política como guerra é a determinação de que se pode suspender as leis em nome da lei, é o passaporte para uma esfera de indeterminação política.

É a política como guerra que fará emergir a ideia de segurança nacional, instituída na era Vargas mediante a implementação da Lei no 38, de abril de 1935, que define os crimes contra a ordem política e social, mas ganha espaço após o golpe civil-militar de 1964, principalmente por meio das construções teóricas de geopolíticos brasileiros, no interior da Escola Superior de Guerra, como o General Golbery do Couto e Silva (1955, p. 22), o qual chega afirmar que:

[...] no amplo quadro da Política Nacional, o Desenvolvimento e a Segurança intimamente se entrosam, reciprocamente se condicionam e acentuadamente se interdependem, chegando mesmo, por vezes, a se confundir numa faixa de recobrimento.

A geopolítica de Golbery (1967, p. 47), que também tinha a intenção de "inundar de civilização a Hiléia amazônica", expressa-se claramente nas palavras de Castelo Branco, por ocasião de sua aula inaugural do ano letivo de 1967, na Escola Superior de Guerra. Diz o primeiro presidente após o golpe civil militar de 1964:

\begin{abstract}
o conceito tradicional de defesa nacional coloca mais ênfase sobre os aspectos militares da segurança e, correlatamente, sobre os problemas de agressão externa. A noção de segurança é mais abrangente. Compreende, por assim dizer, a defesa global das instituições, incorporando, por isso, os aspectos psicossociais, a preservação do desenvolvimento e da estabilidade política interna; além disso, o conceito de segurança, muito mais explicitamente que o de defesa, toma em linha de conta a agressão interna, corporificada na infiltração e subversão ideológica (CASTELO BRANCO, 1983, p. 204).
\end{abstract}

Esses elementos teóricos irão se materializar no Decreto-Lei $\mathrm{n}^{\circ} 314 / 67$, no Ato Institucional $\mathrm{n}^{\circ}$ 5, de dezembro de 1968, bem como na Emenda Constitucional de 1969 e no Decreto-Lei $\mathrm{n}^{\circ}$ 510/69, de modo que todos regulamentam o primeiro decreto de $1967 \mathrm{e}$, fundamentalmente, constroem as diretrizes do que significará a ideia de Segurança Nacional. Os horrores da repressão ganham fôlego e legitimidade jurídica.

Há, então, uma união estável entre segurança e desenvolvimento ou entre "ordem e progresso", que norteará as principais políticas para a Amazônia. A segurança, entendida preliminarmente como defesa, em muito se refere à política externa e defesa de fronteiras, mas a noção de agressão interna, de perigo interno, amplia os sentidos de segurança, atrelando-a a uma 
particular compreensão de desenvolvimento. A formação discursiva que tornou a Amazônia um risco ganha forma político-jurídica.

Um conjunto de políticas ligadas ao Conselho de Segurança Nacional (CSN), nesse contexto, promoveu um processo de militarização do espaço regional amazônico na trilha de um desenvolvimento com "segurança". São dignos de nota a federalização das áreas às margens das rodovias; a criação, em 1980, do Grupo Executivo de Terras do Baixo Amazonas (GEBAM) e do Grupo Executivo de Terras do Araguaia-Tocantins (GETAT), federalizando a questão da propriedade da terra e militarizando os conflitos, destituindo o poder do INCRA na resolução dos conflitos (ALMEIDA, 1981); além de toda a estrutura militar criada para o combate à Guerrilha do Araguaia em meados da década de 1970, que perdurou no controle do garimpo de Serra Pelada pela década de 1980; a criação do Projeto Calha Norte (PCN) em 1985 e do Sistema de Vigilância da Amazônia (SIVAM), hoje Sistema de Proteção da Amazônia (SIPAM), que revelam a preocupação militar do controle das ameaças internas e das fronteiras internacionais.

A própria criação da SUDAM em substituição à SPVEA já sinalizava a centralização das decisões em torno do que seria feito na Amazônia.

Fica bem visível na própria estrutura da SUDAM, particularmente em seu Conselho Deliberativo, o esvaziamento das representações de Estados, territórios e municípios da região. Em contrapartida, estes estão sendo substituídos por representantes de órgãos do poder central (...). Deliberação que foi decisiva na estratégia de afastamento das esferas de poder que poderiam reivindicar espaços no processo de tomada de decisão (CASTRO; ACEVEDO MARIN, 1987, p. 9).

Pelo espectro da política de segurança, a urgência torna-se justificativa de suspensão das regras e, assim, a centralização das decisões transforma a obediência aos poderes instituídos e às leis vigentes uma opção passível de não ser cumprida.

\section{A "EMERGÊNCIA" DOS GRANDES PROJETOS NA AMAZÔNIA}

Para conduzir as políticas de exceção ou a política como guerra, fazia-se necessário a construção de tecnologias políticas capazes de enfrentar o desafio amazônico erguido discursivamente pelo risco e o vazio. Nesse sentido, era necessário construir obras que significassem uma ideia de um Brasil Grande. João Figueiredo, em um discurso proferido em Belém, no dia 27 de outubro de 1982, chega a afirmar que:

Grandes projetos, de magnitude que impressiona a brasileiros e estrangeiros, mas reflete apenas a escala amazônica, desenvolvem-se no Pará: Carajás, Tucuruí, Trombetas, são hoje nomes conhecidos no Mundo inteiro. O seu impacto sobre a economia paraense será imensamente favorável (FIGUEIREDO, 1982, p. 584). 
À escala amazônica, apenas Grandes Projetos podem trazer desenvolvimento. Todavia, não são quaisquer projetos, haja vista a magnitude e a expressão que possuem para impressionar tanto a brasileiros quanto a estrangeiros, tornando-se, mais que projetos, verdadeiros nomes conhecidos. Nestes marcos políticos, se os geógrafos e demógrafos terão um papel decisivo na definição de uma imagem de Amazônia como um vazio marcado por seus atributos naturais, serão os economistas e engenheiros que, contudo, darão sustentação científica e técnica para a condução de políticas de desenvolvimento por Grandes Projetos.

É a economia regional, em seu sentido normativo, que irá consolidar um saber técnico para embasar o que será denominado como planejamento regional. Neste momento, a teoria dos pólos de crescimento, de François Perroux, delineará esses caminhos ao pensar a industrialização como o fator responsável para as variações da estrutura econômica nacional, tomando uma indústria motriz como processo indutor de crescimento (PERROUX, 1967).

Um dos esquemas característicos da operação é o seguinte: um centro de extração de matéria-prima está combinado com um centro de produção de energia e, por vias de comunicação, com centros intermediários ou de transformação. [...] O pólo complexo exige novas criações, abala regiões e altera a estrutura do meio que anima (PERROUX, 1975, p. 100-101).

A ideia de desenvolvimento via industrialização, expressa, por exemplo, a partir da formulação do Programa de Polos Agropecuários e Agrominerais da Amazônia (POLAMAZÔNIA), responsável por demarcar uma estratégia seletiva quanto à criação de 15 polos de desenvolvimento regional, pode ser considerada um protótipo das ideias de Perroux; protótipo este que irá lançar para a Amazônia uma série de projetos que mudarão violentamente a geografia e a história da região ${ }^{12}$.

Mas se a economia regional sugeriu o desenvolvimento via criação de pólos, a engenharia precisou tornar viável tal processo, e aqui entra em cena Eliezer Batista, ex-presidente da Companhia Vale do Rio Doce no início da década de 1960 que, não por motivo qualquer, foi chamado de volta ao cargo pelo presidente militar João Figueiredo, no ano de 1979. Eliezer poderia possibilitar uma logística viável para o desafio colocado pelos polos de desenvolvimento nesse contexto, foi o que fez, então no Projeto Ferro Carajás, articulando com os japoneses para ensejar a criação de demanda e a aquisição de recursos ao projeto, bem como no desenho de uma ferrovia da serra de Carajás, no Pará, até São Luis, no Maranhão, articulada a um porto (Porto de Itaqui) que

\footnotetext{
${ }^{12}$ A indústria escolhida, pelos recursos minerais existentes, foi a extrativa mineral. A energia, também pela imagem dos recursos hídricos infinitos, será produzida por meio das usinas hidrelétricas. E as atividades de transformação industrial serão aquelas de maior consumo de energia, como a produção do alumínio, que demanda imensa quantidade de energia elétrica, ou a siderurgia, que demanda imensa quantidade de carvão vegetal e/ou mineral. 
escoasse o minério de forma racional. Um polo de desenvolvimento transformava-se em um eixo regional de exportações ${ }^{13}$.

Se os polos tentam disciplinar os espaços a partir de uma matriz industrial, pensando a articulação de distintas áreas produtivas como caminho de desenvolvimento, os eixos criam caminhos para responder aos problemas de distribuição/circulação e, assim, alargam seus espaços de interferência, viabilizando fluxos de matéria e energia ao passo que afetam territórios e territorialidades, distintas de sua racionalidade.

A ideia do Brasil Grande ${ }^{14}$, representada na Amazônia por meio da lógica de criação de Grandes Projetos, consolida a tecnologia política dos eixos de exportação; tecnologia esta que passará a ser a feição "moderna” (moderno-colonial) de nossas plantations, uma vez que a lógica de acumulação rentista pelo o alargamento da apropriação de terras, de recursos naturais e de toda sorte de bens públicos e coletivos, encontrará um novo modo de drenar matéria e energia, que continuará como consenso de Estado no Brasil, atravessando distintas forças políticas, de direita e de esquerda.

Essa maneira de ver pela grandeza de projetos, vale dizer, encadeia leituras de mundo a partir de um centro de onde parte o olhar: os processos de modernização capitalistas, que são também de colonialidade, do poder (QUIJANO, 2009), do saber (LANDER, 2009), do ser (MALDONADO-TORRES, 2007) e da natureza (WALSH, 2012) ${ }^{15}$

Políticas como o "Avança Brasil" e "Brasil em Ação", concebidas por ocasião dos governos de Fernando Henrique Cardoso (FHC), nos anos 1990, como uma maneira de possibilitar o acesso competitivo das commodities brasileiras aos mercados internacionais, consolidaram o

\footnotetext{
${ }^{13}$ Sobre essas estratégias de "modernização" regional, Coelho et al (2005) chamam a atenção para a existência de dois grupos de estratégias de modernização regional que marcaram e marcam a história recente da Amazônia, isso porque "Enquanto um deles consistiu nas tentativas de estabelecimento de pólos de crescimento econômico e de complexos industriais motrizes, o outro diz respeito aos esforços para estimular eixos estruturadores de desenvolvimento regional. Ambos se baseiam em postulados teóricos distintos. No primeiro grupo de estratégias, julga-se ser necessária a participação estatal para contra arrestar dinâmicas produzidas pelo mercado, considerando-se que a modernização de certas regiões não ocorreria sem a ação do Estado. Já o segundo grupo integra estratégias de desenvolvimento regional baseadas no suposto da eficácia das dinâmicas de mercado" (COELHO et al., 2005, p. 74).

${ }^{14} \mathrm{Em}$ resposta a muitas críticas feitas ao projeto Carajás, Eliezer Batista recupera a noção de Brasil Grande para justificar Grandes Projetos, afirmando que: "Só posso atribuir a campanha contra Carajás ao fermento da ignorância, que faz muitas vezes confundirmos o interesse individual como prioritário em detrimento do bem maior. O projeto consolidou o Brasil como um player global no setor de mineração em uma época em que ninguém falava de empresa ou economia globalizadas. Conquistamos o mercado internacional por méritos próprios, batendo de frente com concorrentes e países muito mais desenvolvidos e em melhores condições financeiras. Carajás foi à vitória de um Brasil grande sobre um Brasil que insiste em ser minúsculo" (FARO; POUSA; FERNANDEZ, 2005, p. 135).

15 Para Catherine Walsh (2012), a razão neoliberal se manifesta a partir de quatro formas distintas e integradas de colonialidade: a) a colonialidade do poder, que estabelece um sistema de classificação social hierárquico em termos de raça e gênero; b) a colonialidade do saber, que impõe o eurocentrismo como a perspectiva única de conhecimento, descartando a existência e viabilidade de outras racionalidades epistêmicas; c) a colonialidade do ser, que se exerce por meio da inferiorização, des-humanização e fetichização do ser humano; e d) a colonialidade da mãe natureza, que, ao dissociar razão, cultura, sociedade e natureza, impõe uma lógica de ver, sentir e pensar o mundo, tendo o humano como dissociado da mãe natureza (WALSH, 2012).
} 
esboço desse "Brasil Grande". Ao final de sua gestão, no ano de 2002, FHC tece as seguintes afirmações:

Daí a definição do Avança Brasil primeiro, o Brasil em Ação, depois [...]. Ao invés de pensarmos na concentração numa certa área ou numa certa atividade para daí, em círculos progressivos, haver o crescimento de todos, achamos que seria melhor organizar as nossas idéias em função de certos eixos de desenvolvimento. Aí estão os eixos fundamentais de desenvolvimento nacionais, de integração e desenvolvimento (CARDOSO, 2002, não paginado).

A necessidade de maior fluidez do capital transforma a lógica de integração e desenvolvimento, historicamente presentes como respostas ao risco e vazio amazônicos, no estabelecimento de eixos que transformam a complexidade e diversidade regional no caminho do gado, do ferro, da soja, do milho, das águas...

Luiz Inácio Lula da Silva - também colocando a roda do capitalismo à brasileira para girar pelo rentismo da expansão das commodities e pelos ganhos estratosféricos do sistema bancáriofinanceiro $^{16}$ - em discurso, durante a cerimônia de inauguração do projeto de exploração de cobre "Sossego", em Canaã dos Carajás, em 2004, define a importância da exportação de commodities para a economia brasileira:

Aqui em Carajás, debaixo deste solo, existem riquezas imensas que têm contribuído muito para o desenvolvimento e o progresso social do nosso querido Brasil [...]. A alavanca exportadora, uma das mais destacadas prioridades do nosso governo, tem alcançado objetivos extraordinários [...]. Os pólos exportadores que dependem de boas estradas, portos profundos e muita energia, entre outros fatores, são fortes indutores de desenvolvimento infra-estrutural (LULA DA SILVA, 2004, não paginado).

A alavanca exportadora se traduz em polos exportadores que dependem de grandes obras de infraestrutura para funcionar. Na Amazônia, o Programa de Aceleração do Crescimento (PAC) e os investimentos diretos do Banco Nacional de Desenvolvimento Econômico e Social (BNDES), viabilizaram políticas voltadas à consolidação e criação de eixos de exportação.

Entretanto, se a exportação de commodities por meio dos eixos de exportação atravessou as políticas nacionais pensadas para a Amazônia de distintos governos e bandeiras partidárias no Brasil, será que a centralização das decisões características dessas políticas, que, por sua vez, normaliza a suspensão das leis, permanece inalterada mesmo em regimes democráticos?

Se nos governos militares as lógicas autoritárias de se realizar a política se justificavam pela ideia de segurança nacional, encarnada pela formação discursiva da Amazônia como risco e vazio, agora, a força da ideia de interesse nacional, alimentada por uma imagem de nação herdeira

${ }^{16} \mathrm{O}$ "boom" do preço das commodities no início do século XXI impulsionou distintos governos na América Latina, dentre eles o Brasil, a conduzir a política econômica pela exportação de produtos agrícolas e minerais como o caminho absoluto para a conquista do superávit primário. 
da mesma formação discursiva anterior, irá conferir tons de normalidade a práticas de exceção. Por isso, o planejamento de Grandes Projetos para a Amazônia é, historicamente, a abertura da excepcionalidade para a política, pela delimitação de uma zona de indiferença para qual tudo se justifica.

Ainda na década de 1990, Lux Vidal (1991, p. 68) afirmara, a partir de seu trabalho com os povos indígenas nas influências do projeto Carajás, que "os processos decisórios que têm levado à implementação de projetos como o PGC se fizeram à revelia da sociedade brasileira", uma vez que “[os] debates supostamente democráticos são sempre feitos após os fatos consumados” (VIDAL, 1991, p. 68).

Mas há um caso exemplar que atravessa governos e racionalidades políticas e marca a exceção como regra política para a Amazônia. Estamos falando da proposta de criação do Complexo Hidrelétrico de Altamira, ainda na década de 1980, que seria chamado de Kararaô. Viveiros de Castro e Andrade (1988, p. 7) definem bem a condução desse primeiro processo:

Desde que, numa perversão característica do discurso dos planejadores governamentais, os índios são um 'problema ambiental', para as grandes obras de engenharia, não é surpreendente constatar que nenhum dos povos mencionados foi consultado a respeito de decisões que afetam as bases de sua sobrevivência.

A hidrelétrica de Kararâ̂ foi barrada por movimentos indígenas e problemas técnicos para a execução do projeto, tendo a imagem da Índia Tuíra, com um terçado no rosto do então diretor de engenharia da Eletronorte, José Antônio Muniz Lopes, como um símbolo da resistência. Entretanto, depois de anos do fim da ditadura militar, a hidrelétrica ressurgia batizada de Belo Monte para ser mais uma expressão da lógica de exceção a marcar os projetos na Amazônia. Depois que o diretor de Licenciamento Ambiental do Ibama, Sebastião Pires, e o Coordenador Geral de Infraestrutura Elétrica, Leozildo Benjamin, pediram demissão, após serem pressionados pelo governo federal para liberarem a licença ambiental da hidrelétrica, após um Estudo de Impacto Ambiental de mais de 35 mil páginas e de algumas suspensões da licença de operação da obra, Belo Monte continuou a ser executada à revelia das condicionantes exigidas.

Em depoimento à jornalista Eliane Brum, Thais Santi, procuradora da república, sintetiza bem os processos de excepcionalidade em Belo Monte:

Você tem uma opção governamental, uma opção política do governo por construir grandes empreendimentos, enormes, brutais, na Amazônia [...] Mas é uma opção que se sustenta na legitimidade do governo [...]. Agora, uma vez adotada essa política, feita essa escolha governamental, o respeito à Lei não é mais uma opção do governo. O que aconteceu e está acontecendo em Belo Monte é que, feita a escolha governamental, que já é questionável, o caminho para se implementar essa opção é trilhado pelo governo como se também fosse uma escolha, como se o governo pudesse optar entre respeitar ou não as regras do licenciamento (SANTI apud BRUM, 2014, não paginado). 
Transformar a observância às leis demonstra em escolha política define bem o modus operandi dos ditos Grandes Projetos na Amazônia. O fato é que foi mais confortável nesse "Brasil" setentrional criar mecanismos de governo diretamente ligados ao Estado Central, dispositivos de exceção que, em nome da excepcionalidade que a região pretensamente exigiria, dá carta branca a qualquer ação ou vontade política. Se a estrutura topológica do estado de exceção é, segundo Agamben (2004, p. 57), interiorizar o que está fora, ou ainda, é um "estar fora e, ao mesmo tempo, pertencer", essas zonas de indiferença produzidas por esses dispositivos de exceção criam um espaço vazio de direito em que a própria distinção entre público e privado está desativada, um conjunto de ficções no qual o direito inclui, em si, sua própria ausência, criando, enfim, um não lugar absoluto, onde se estrutura o impensável na ordem jurídica, instituindo a política como guerra.

Não esqueçamos os mais de 4 mil requerimentos de processos minerários em terras indígenas entre 1969 e 2016 no Brasil, valendo a lembrança que 98\% das terras indígenas estão na Amazônia (BARROS; BARCELOS; BRESSANE, 2016). Também não esqueçamos as mais de 23 mil pessoas desalojadas pela UHE de Tucuruí, as mais de 10 mil famílias desalojadas pela UHE de Belo Monte, além de tantos outros processos de deslocamento compulsório por Usinas Hidrelétricas na Amazônia. Não esqueçamos, ainda, a violência brutal dos processos de mineração nos territórios Yanomami, Waimiri Atroari, Cinta Larga, dentre muitos outros povos indígenas, além das marcas nos corpos de múltiplos sujeitos coletivos deixadas por grandes obras logísticas, como nas 88 comunidades quilombolas, nas 4 terras indígenas e nas mais de 100 outras comunidades recortadas pela Estrada de Ferro Carajás entre o Pará e o Maranhão (MALHEIRO, 2019).

Deste modo, os Grandes Projetos se constituem como uma maneira particular e racional de manipulação das relações de força, pois demonstram uma maneira específica de governar que estrutura a ação de quem quer que seja a partir de sua racionalidade, expressam-se, portanto, como tecnologias políticas de exceção que levam a realização dos processos políticos a uma esfera de indeterminação legitimando a realização de processos econômicos pela via da violência.

\section{6. À GUISA DE CONCLUSÃO}

As cartas de Marquês de Pombal sobre os riscos que a porção setentrional da América Portuguesa representava à unidade do Estado Português, que expressam o poder exercido pelas ordens religiosas sobre as populações indígenas como um risco sério à soberania ainda no século XVIII, delimitam a necessidade de uma nova arte de governar a província para assegurar a soberania e fazer florescer o comércio. Tal modo de compreender marca a emergência, de um lado, de uma razão do Estado absolutamente distinta do pastorado das ordens religiosas, ao passo que constrói um a priori histórico que conduzirá o modo de ver e dizer sobre essa parte setentrional da 
América Portuguesa, que hoje chamamos de Amazônia. População, riqueza, segurança e território serão as matrizes dessa razão, o que vai representar, emprestando os termos de Foucault (2008), uma desgovernamentalização do cosmos para uma governamentalização do Estado.

Esse modo de ver uma região como um risco à soberania, sobretudo porque sua fisionomia natural e sua diversidade étnica e lingüística representavam uma exterioridade ao que vai se definir como a nação, transforma esse estado de não existência na condição de existência do Estado, aí de exceção.

Esse modo de ver estrutura um diagrama de poder: ao risco do vazio e imaturo espaço natural, ergue-se um desafio amazônico, que só pode ser respondido pela razão do Estado por meio de intervenções que precisam significar, em grandeza, o tamanho do desafio amazônico. Nesses termos, em nome da inclusão desse fora absoluto - a Amazônia - a ficção nacionalista se vestirá de políticas de valorização (riqueza) da natureza insólita, de povoamento (população) do vazio demográfico e racional, de defesa (território) da nação frente à imaturidade dos gentios, e de garantia da soberania nacional (segurança) frente ao risco amazônico. Assim, pelas marcas do colonialismo interno, o estado de exceção torna-se uma regra e a política um ato de guerra.

Mas se Agamben $(2002$, 2004) identifica os campos de concentração como principais paradigmas biopolíticos do Estado de Exceção, ou mesmo Achile Mbembe (2016) identifica as plantations coloniais como os paradigmas do estado de exceção, antes mesmo dos campos de concentração, podemos dizer ser os Grandes Projetos paradigmas fundamentais na compreensão do Estado de Exceção na Amazônia, uma vez que estamos falando de processos capitalistas que se realizam suspendendo vidas, estruturando uma maneira específica de governo do território, interligando discursos, instituições e disposições espaciais fora do ordenamento jurídico.

Os Grandes Projetos tornam-se, portanto, paradigmas do estado de exceção na Amazônia, pois são dispositivos moderno-coloniais que atualizam o sentido das plantations ou realizam a lógica do campo, não apenas por desempenharem a drenagem de matéria e energia por meio do saque neocolonial e reproduzirem a dependência como mote de integração global, mas por tornarem possível o uso da violência como processo de acumulação de um capitalismo financeirizado, por tornarem possível a expropriação das condições de existência e energias vitais de povos e comunidades tradicionais como lógica legitimada de desenvolvimento, tornando o sacrifício, a destruição e a morte em caminhos naturalizados do que, colonialmente, institui-se como progresso.

Assim sendo, vale dizer que esses mecanismos de definição do risco e do vazio, que demarcam a excepcionalidade da Amazônia em relação ao Brasil, podem ser lidos como uma maneira de distribuição espacial das práticas de violência do Estado. Nesses termos, assim como a Amazônia se torna um risco à nação, outros espaços também assumem essa alcunha na dinâmica de produção e justificação da morte pelo Estado brasileiro. Dessa forma, seja na Amazônia ou nas DOI 10.5752/p.2318-2962.2020v30n60p74 
periferias de grandes cidades, o medo, que produz a ideia de risco, além da indiferença, que a noção de vazio cria, estruturam uma geografia de exceção em que a garantia da vida e da segurança de alguns espaços se estrutura pela morte regulada em outros espaços; estes últimos, definidos como zonas de sacrifício a partir de cortes de raça, classe e gênero.

Poderíamos mesmo sugerir que essa geografia de exceção fosse entendida por processos de territorialização de exceção, nos quais a criação de mediações espaciais, que proporcionem acesso a recursos e/ou domínio de terras, passam por dinâmicas de suspensão normativa, criando dispositivos, com claros recortes raciais e étnicos, de gestão de populações, numa lógica de ação que estrutura/define/interdita o campo de ação e a possibilidade de criação de mediações espaciais de outros grupos sociais, os quais, definidos por um menor valor, tornam-se politicamente matáveis e territorialmente invisíveis e dispensáveis.

\section{REFERÊNCIAS}

AGAMBEN, G. Homo Sacer: o poder soberano e a vida nua I. 1. ed. Belo Horizonte: Editora UFMG, 2002. 197p.

AGAMBEN, G. Estado de exceção. Tradução de Iraci D. Poleti. 1. ed. São Paulo: Boitempo, 2004. $143 p$.

AGAMBEN, G. Meios sem fim: notas sobre a política. Tradução de Davi Pessoa. 1. ed. Belo Horizonte: Autêntica, 2015. 136p.

ALBUQUERQUE JR., D. M. A invenção do Nordeste e outras artes. 3. ed. Recife: FJN, Ed. Massangana; São Paulo: Cortez, 2006. 376p.

ALMEIDA, A. W. B. GETAT - Segurança nacional e o revigoramento do poder regional. Reforma Agrária (Boletim da Abra), Campinas, v. 11, n. 2, p. 24-41, 1981.

ALMEIDA, A. W. B. Antropologia dos archivos da Amazônia. Rio de Janeiro: Casa 8/Fundação Universidade do Amazonas, 2008. 192p.

ANDERSON, B. Comunidades Imaginadas: reflexões sobre a origem e a difusão do nacionalismo. 1. ed. São Paulo: Companhia das Letras, 2008. 336p.

BARROS, C.; BARCELOS, I.; BRESSANE, C. Em terra de índio mineração bate à porta. Publica, São Paulo. Disponível em: <https://apublica.org/2016/06/em-terra-de-indio-a-mineracao-bate-aporta-2/>. Acesso em: 04 jul. 2019.

BORON, A. A.; AMADEO, J.; GONZÁlEZ, S. (Org.). A teoria marxista hoje: problemas e perspectivas. Buenos Aires: Consejo Latinoamericano de Ciencias Sociales-CLACSO, 2006. 528p.

BRUM, E. Belo Monte: a anatomia de um etnocídio. El País, São Paulo, dez. 2014. Opinião. Disponível em: <https://brasil.elpais.com/brasil/2014/12/01/opinion/1417437633_930086.html>. Acesso em: 28 jan. 2019. 
CARDOSO, F. H. Discurso do Presidente da República, Fernando Henrique Cardoso, na reunião ministerial - Programa de Trabalho para 2002. PSDB, São Paulo, 07 fev. 2002. Disponível em: <http://www.psdb.org.br/pe/discurso-do-presidente-da-republica-fernando-henrique-cardoso-nareuniao-ministerial-programa-de-trabalho-para-2002/>. Acesso em: 22 jan. 2019.

CASTElo BRANCO, H. A. Escola Superior de Guerra: manual básico. Rio de Janeiro: ESG, 1983.

CASTORIADIS, C. A instituição imaginária da sociedade. 3. ed. Rio de Janeiro: Paz e Terra, 1982. 418p.

CASTRO, E. M. R.; ACEVEDO MARIN, R. E. Estado e poder local: dinâmicas das transformações da Amazônia brasileira. Pará-desenvolvimento: a face social dos grandes projetos, Belém, n. 20-21, p. 9-12, 1987.

CASTRO-GÓMES, S. Ciências sociais, violência epistêmica e o problema da invenção do outro". In: LANDER, E. (Org.). A colonialidade do saber: eurocentrismo e ciências sociais, perspectivas latino-americanas. Buenos Aires: CLACSO, 2005, p. 169-186.

CHAUÍ, M. Brasil. Mito fundador e sociedade autoritária. 1. ed. São Paulo: Editora Perseu Abramo, 2004. 103p.

COELHO, M. C. N.; MONTEIRO, M. A.; LOPES, A.; BACURI, S. Regiões do entorno dos projetos de extração e transformação mineral na Amazônia Oriental. Novos Cadernos NAEA, Belém, v. 8, n. 2, p. 73-107, 2005.

COUTO E SILVA, G. Planejamento estratégico. 2. ed. Campinas: UNICAMP/IFCH, 1955. 536p.

COUTO E SILVA, G. Geopolítica do Brasil. 1. ed. Rio de Janeiro: Livraria José Olympio, 1967. $132 \mathrm{p}$.

CUNHA, M. C. Índios no Brasil: história, direitos e cidadania. São Paulo: Claro Enigma, 2012. $156 \mathrm{p}$.

DUTRA, M. A natureza da TV: uma leitura dos discursos da mídia sobre a Amazônia, biodiversidade, povos da floresta... Belém: NAEA/UFPA, 2003. 279p.

FARO, L. C; POUSA, C.; FERNANDEZ, C. Conversas com Eliezer. Rio de Janeiro: Insight Engenharia de Comunicação, 2005. 243p.

FIGUEIREDO, J. Presidente do Brasil: discursos. v. 4. Tomo II. Brasília: Presidência da República, 1982.

FOUCAULT, M. Segurança, território, população. 1. ed. São Paulo: Martins Fontes, 2008. 572p.

GONDIM, N. A invenção da Amazônia. 1. ed. São Paulo: Marco Zero, 2004. 340p.

GONZÁLEZ CASANOVA, P. Colonialismo interno (uma redefinição). In: BORON, A. A.; AMADEO, J.; GONZÁLEZ, S. (Org.). A teoria marxista hoje: problemas e perspectivas. Buenos Aires: Consejo Latinoamericano de Ciencias Sociales-CLACSO, 2006. p. 431-458. 
GONZÁLEZ CASANOVA, P. De la sociología del poder a la sociología de la explotación: pensar América Latina en el siglo XXI. 21. ed. Buenos Aires: CLACSO, 2015. 464p.

GRAMSCI, A. Os cadernos do cárcere. Maquiavel. Notas sobre o Estado e a política - volume 3. Rio de Janeiro: Civilização Brasileira, 2002. 432p.

LANDER, E. Ciências sociais: saberes coloniais e eurocêntricos. In: LANDER, E. (Org.). A colonialidade do saber: eurocentrismo e ciências sociais, perspectivas latino-americanas. Buenos Aires: CLACSO, 2005. p. 169-186.

LULA DA SILVA, L. I. Discurso do Presidente da República, Luiz Inácio Lula da Silva, na cerimônia de inauguração da mina de cobre do Sossego Canaã dos Carajás-PA. Presidência da República. Brasília, DF: Secretaria de Imprensa e Divulgação, 2004. Disponível em: $<$ http://www.biblioteca.presidencia.gov.br/presidencia/ex-presidentes/luiz-inacio-lula-dasilva/discursos/1o-mandato/2004/02-07-2004-discurso-do-presidente-da-republica-luiz-inacio-lulada-silva-na-cerimonia-de-inauguracao-da-mina-de-cobre-do-sossego>. Acesso em: 25 jan. 2019.

MALDONALDO-TORRES, N. Sobre la colonialidad del ser: contribuciones al desarrollo de un concepto. In: CASTRO-GÓMES, S.; GROSFOGUEL, R. (Org.). El giro decolonial: reflexiones para una diversidad epistémica más allá del capitalismo global. Bogotá: Siglo del Hombre Editores, 2007. p. 127-167.

MALHEIRO, B. C. P. O que Vale em Carajás? Geografias de exceção e r-existência pelos caminhos do ferro na Amazônia. 2019. 439 f. Tese (Doutorado em Geografia) - Programa de PósGraduação em Geografia, Universidade Federal Fluminense, Niterói, 2019.

MBEMBE, A. Necropolítica. Arte \& Ensaios, Rio de Janeiro, n. 32, p. 123-151, 2016.

MELO, S. J. C. República jesuítica ultramarina. Gravataí: SMEC;, 1989. 38p.

MIGNOLO, W. D. Histórias locais/ Projetos globais. Belo Horizonte: Editora da UFMG, 2003. $505 \mathrm{p}$.

MOREIRA, E. Amazônia: o conceito e a paisagem. Belém: Instituto Nacional de Pesquisas da Amazônia, 1958. 91p.

OLIVEIRA, R. C. Aculturação e “fricção interétnica”. América Latina, São Paulo, v. 6, n. 3, p. 3346, 1963.

OLIVEIRA, R. C. O índio e o mundo dos brancos. 4. ed. Campinas: Ed. da Unicamp, 1996. 200p.

PACHECO DE OLIVEIRA, J. O nascimento do Brasil e outros ensaios: "pacificação", regime tutelar e formação da alteridade. Rio de Janeiro: Contra Capa, 2016. 384p.

PEREIRA, E. A. Ensaios de Amazônia: Representações espaciais da região no ensaísmo brasileiro. 1. ed. Niterói: EDUFF, 2016. 204p.

PERROUX, F. A economia do século XX. Tradução de José Lebre de Freitas. Lisboa: Herder, 1967. 783p.

PERROUX, F. O conceito de polos de crescimento. In: FAISSOL, S. (Org.). Urbanização e regionalização: relações com o desenvolvimento econômico. Rio de Janeiro: IBGE, 1975. p. 99110. 
PIZARRO, A. Amazônia: as vozes do rio. Belo Horizonte: Editora da UFMG, 2012. 271p.

PORTO-GONÇALVES, C. W. Amazônia, Amazônias. 3. ed. São Paulo: Contexto, 2005. 177p.

QUIJANO, A. Colonialidade do poder e classificação social. In: SANTOS, B. S.; MENEZES, M. P. (Org.). Epistemologias do Sul. Coimbra: Almedina, 2009. p. 73-118.

SOARES, L. C. Amazônia. Rio de Janeiro: Conselho Nacional de Geografia, 1963. 125p.

SOUSA SANTOS, B. A gramática do tempo. São Paulo: Cortez, 2008. 512p.

SOUZA, M. Amazônia indígena. Rio de Janeiro: Record, 2015. 212p.

SPVEA. Perspectiva do Primeiro Plano Quinquenal e Concepção Preliminar da Valorização Econômica da Amazônia. Belém: Setor de Coordenação e Divulgação, 1954.

SUDAM. Operação Amazônia: discursos. Belém: SUDAM/Serviço de Documentação e Divulgação, 1968.

VIDAL, L. B. Os índios da Amazônia: um desafio recíproco. In: HÉBETTE, J. (Org.). O cerco está se fechando. Rio de Janeiro: Vozes, 1991. p. 54-77.

VIVEIROS DE CASTRO, E.; ANDRADE, L. Hidrelétrica do Xingu: o Estado contra as sociedades indígenas. In: SANTOS, L. A.; ANDRADE, L. (Org.). As hidrelétricas do Xingu e os povos indígenas. São Paulo: Comissão Pró-índio de São Paulo, 1988. p. 7-23.

WALSH, C. Interculturalidad crítica y (de)colonialidad: ensayos desde Abya Yala. Quito: Abya Yala - Instituto Científico de Culturas Indígenas, 2012. 234p. 